\title{
Kajian Pustaka: Gambaran Pengetahuan dan Perilaku Masyarakat untuk Mencari Fasilitas Kesehatan dalam Penanganan Penyakit Tuberkulosis
}

\author{
Meira Erawati $^{1^{*}}$, Ireneus Pape No Mbeong ${ }^{1}$ \\ ${ }^{1}$ Departemen Ilmu Keperawatan Fakultas Kedokteran, Universitas Diponegoro, Semarang, Indonesia \\ meiraerawati@gmail.com
}

\begin{abstract}
Introduction: The knowledge and behavior of the community in seeking health facilities for the treatment of tuberculosis were studied separately by previous researchers, so it is necessary to do a literature review to get a complete picture of this phenomenon. This study aims to obtain an overview of knowledge about tuberculosis and the behavior of people seeking health facilities in the treatment of tuberculosis in various previous studies.

Methods: The study was a literature review. The sample of this study was eight articles, with inclusion criteria i.e. published in journals in the last 10 years, descriptive research, and full text. The articles were obtained through the search engines Science Direct, Scopus and Ebsco Host. The literature analysis was carried out by means of a narrative review and presented in a table.

Results: The level of public knowledge about the causes of tuberculosis, signs and symptoms of the disease, modes of transmission, ways to prevent transmission, as well as knowledge that tuberculosis can be cured varied from low to high levels of knowledge. People take advantage of government and private health services, buy drugs at pharmacies, and go to traditional healers/traditional healers to get treatment for tuberculosis.

Conclusion: There are still public misunderstandings about tuberculosis and obstacles in utilizing health facilities for the treatment of tuberculosis. Therefore, health education and counseling need to be improved so that public knowledge related to tuberculosis is getting better and has a positive impact on the behavior of seeking health facilities in the treatment of tuberculosis. It is necessary to conduct further studies on the factors that underlie people's behavior in seeking health facilities in the treatment of tuberculosis.
\end{abstract}

Keywords: Behavior, community, health seeking, knowledge, tuberculosis.

\begin{abstract}
Abstrak
Pendahuluan: Tingkat pengetahuan dan perilaku masyarakat dalam mencari fasilitas kesehatan untuk penanganan tuberkulosis diteliti secara terpisah oleh para peneliti terdahulu, sehingga perlu dilakukan kajian pustaka untuk mendapatkan gambaran secara utuh tentang kedua fenomena tersebut. Penelitian ini bertujuan untuk mendapatkan gambaran pengetahuan tentang tuberkulosis dan perilaku masyarakat mencari fasilitas kesehatan dalam penanganan penyakit tuberkulosis pada berbagai hasil penelitian sebelumnya.

Metode: Penelitian ini menggunakan metode kajian pustaka. Sampel dari penelitian ini berjumlah 8 artikel, dengan kriteria inklusi: diterbitkan di jurnal ilmiah 10 tahun terakhir, penelitian deskriptif, dan dapat diakses dalam bentuk fulltext. Artikel penelitian didapatkan melalui mesin pencarian Science Direct, Scopus dan Ebsco Host. Analisis kepustakaan dilakukan dengan narrative review dan ditampilkan dalam tabel.
\end{abstract}


Hasil: Tingkat pengetahuan masyarakat tentang penyebab tuberkulosis, tanda gejala penyakit, cara penularan, cara pencegahan penularan, serta pengetahuan bahwa tuberkulosis bisa disembuhkan bervariasi mulai dari tingkat pengetahuan rendah sampai tinggi. Masyarakat memanfaatkan pelayanan kesehatan milik pemerintah dan swasta, membeli obat di apotek dan pergi ke dukun/tabib tradisional untuk mendapatkan pengobatan tuberkulosis.

Kesimpulan: Masih terdapat kesalahpahaman masyarakat tentang penyakit tuberkulosis dan kendala dalam memanfaatkan fasilitas kesehatan untuk penanganan tuberkulosis. Pendidikan kesehatan perlu ditingkatkan agar pengetahuan masyarakat terkait tuberkulosis semakin baik dan berdampak positif pada perilaku mencari fasilitas kesehatan dalam penanganan tuberkulosis. Perlu kajian lebih lanjut tentang faktor yang mendasari perilaku masyarakat dalam mencari fasilitas kesehatan dalam penanganan tuberkulosis.

Kata kunci: Masyarakat, pengetahuan, perilaku, pencarian kesehatan, tuberculosis.

\section{PENDAHULUAN}

Tuberkulosis (TBC) merupakan penyakit infeksi menular yang disebabkan oleh bakteri Mycobacterium tuberculosis. Masyarakat beranggapan bahwa penyakit TBC paru disebabkan merokok, minum alkohol, debu, udara dingin, sihir, trauma di dada, kontak dengan ternak dan faktor genetik (Mbuthia, Olungah, \& Ondicho, 2018). Survei prevalensi TBC tahun 2017, menunjukkan kejadian TBC di Indonesia sebesar 319 per 100.000 penduduk dengan total kasus mencapai 842.000 (World Health Organization [WHO], 2018).

Beberapa penyebab penyakit tuberkulosis dapat ditularkan kepada orang lain antara lain kurangnya pengetahuan masyarakat tentang penyakit tuberkulosis dan perilaku masyarakat yang tidak segera mencari fasilitas kesehatan untuk mendapatkan penanganan penyakit tuberkulosis. Pengetahuan tentang tuberkulosis paru adalah sejauh mana masyarakat mengetahui tentang definisi tuberkulosis, penyebab, tanda dan gejala, pengobatan serta pencegahan penularan tuberkulosis paru (Agustina \& Wahjuni, 2017). Ketersediaan fasilitas kesehatan untuk penanganan penyakit tuberkulosis yakni tersedianya pelayanan kesehatan seperti Pusat Kesehatan Masyarakat (Puskesmas), rumah sakit, dan pelayanan kedokteran yang dikelola oleh perseorangan yaitu dokter praktik dan klinik (Mursyaf, Nurdiyanah, \& Ibrahim, 2018). Pengetahuan keluarga yang baik tentang tuberkulosis dipengaruhi oleh informasi yang diterima (formal dan non formal), tingkat pendidikan, usia dan lingkungan. Pengetahuan yang kurang dapat terjadi karena kurangnya informasi formal maupun non formal maupun tidak adekuatnya informasi tentang tuberkulosis yang diperoleh keluarga (Nurfadillah, Indra, \& Restuastuti, 2014). Keterlambatan pencarian fasilitas kesehatan untuk mendapatakan perawatan dan pengobatan penyakit tuberkulosis dipengaruhi oleh ketidaktahuan tentang bahaya penyakit tuberkulosis (Oladayo et al., 2014).

Beberapa alasan masyarakat tidak segera mencari fasilitas kesehatan untuk mendapatkan penanganan penyakit tuberkulosis antara lain dipengaruhi oleh stigma dan persepsi masyarakat yang salah tentang tuberkulosis. Masyarakat percaya bahwa tuberkulosis dapat disembuhkan dengan pengobatan modern dan pengobatan tradisional (Nyasulu et al., 2015). Alasan lain yang mendasari masyarakat tidak segera mencari fasilitas kesehatan untuk mendapatkan penanganan penyakit tuberkulosis adalah jarak yang 
jauh antara rumah dan fasilitas kesehatan, tidak adanya asuransi kesehatan, tidak adanya biaya untuk berobat ke fasilitas kesehatan dan masih ada stigma negatif terhadap tuberkulosis di masyarakat yang berpengaruh ke pencarian pengobatan yang terlambat (Dodi, Setiawati, \& Soeroto, 2017). Perilaku masyarakat segera mencari fasilitas kesehatan berfungsi untuk pencegahan penularan kepada orang lain. Selain itu pencarian fasilitas kesehatan bermanfaat agar penyakit tuberkulosis yang diderita tidak semakin parah yang dapat mengakibatkan kematian. Penelitian yang dilakukan di Nigeria, tentang persepsi masyarakat pada tuberkulosis dan pengaruhnya terhadap perilaku mencari kesehatan menyebutkan bahwa orang yang percaya bahwa penyakit tuberkulosis yang disebabkan oleh kuman biasanya mencari perawatan kesehatan di fasilitas kesehatan yang resmi, sedangkan masyarakat yang percaya bahwa tuberkulosis disebabkan oleh kekuatan supranatural, seperti kutukan leluhur dan sihir, biasanya mencari bantuan pada ahli jamu atau pengobatan tradisional. Selain itu pada masyarakat yang percaya bahwa tuberkulosis dapat disembuhkan lebih memungkinkan untuk mencari perawatan kesehatan yang memadai (Kusimo et al., 2015).

Penelitian yang dilakukan di Kabupaten Sikka Flores, menunjukkan bahwa masyarakat mempunyai pengetahuan yang terbatas tentang penyebab, cara penularan, pencegahan dan deteksi dini penyakit tuberkulosis yang dapat berpengaruh pada perilaku mencari pelayanan kesehatan untuk mengobati penyakit tuberkulosis serta upaya untuk mencegah penularan (Dewi, Barclay, Passey, \& Wilson, 2016). Penelitian lain juga yang dilakukan di Bangladesh pada tahun 2013, mengungkapkan bahwa ada kesenjangan pengetahuan masyarakat yang diteliti. Masih terdapat masyarakat yang tidak mengetahui tanda dan gejala tuberkulosis, tidak mengetahui bahwa seseorang dapat menderita tuberkulosis lebih dari sekali dalam seumur hidup, penyakit tuberkulosis dapat menginfeksi anak-anak, tidak tahu bahwa seseorang harus melanjutkan pengobatan bila gejala terus berlangsung selama lebih dari tiga minggu, tidak tahu bahwa enam bulan pengobatan sangat penting untuk penyembuhan dan tidak tahu bahwa tuberkulosis dapat ditularkan selama pengobatan (Paul et al., 2015).

Berbagai upaya untuk meningkatkan pengetahuan masyarakat terkait tuberkulosis dan perilaku masyarakat dalam mencari penanganan penyakit tuberkulosis sudah dijalankan di Puskesmas yakni dengan menjalankan Program Nasional Penanggulangan Tuberkulosis. Berbagai kegiatan untuk penanggulangan tuberkulosis sudah dilakukan di Puskesmas seperti program penyuluhan kesehatan oleh petugas kesehatan dan pengelola program tuberkulosis Puskesmas secara terstruktur melalui Posyandu, kegiatan ketuk pintu rumah penderita tuberkulosis, pelacakan kontak serumah (contact tracing) pada keluarga penderita tuberkulosis, pelacakan tuberkulosis mangkir, tetapi angka kejadian tuberkulosis paru masih cukup tinggi. Berdasarkan data dari kepustakaan yang ada, dapat diketahui bahwa pengetahuan masyarakat tentang penyakit tuberkulosis dan perilaku mencari fasilitas kesehatan dalam penanganan penyakit tuberkulosis masih bervariasi. Tingkat pengetahuan tentang tuberkulosis dan perilaku masyarakat dalam mencari fasilitas kesehatan untuk penanganan tuberkulosis diteliti secara terpisah oleh para peneliti sebelumnya, sehingga perlu dilakukan kajian pustaka untuk mendapatkan gambaran secara utuh tentang kedua fenomena tersebut 


\section{METODE}

Metode yang digunakan dalam penelitian ini adalah kajian pustaka. Artikel yang dikategorikan memenuhi kriteria inklusi yakni artikel yang dipublikasikan sepuluh tahun terakhir (2010-2020), menampilkan data pengetahuan masyarakat tentang penyakit tuberkulosis dan perilaku masyarakat dalam mencari fasilitas kesehatan untuk penanganan penyakit tuberkulosis menggunakan desain penelitian deskriptif, serta dapat diakses dalam bentuk fulltext.

Pencarian artikel menggunakan pertanyaan masalah yang didasarkan pada population/problem,

intervention/indicator, comparation, outcome, study design (PICOS). Population yang ditetapkan adalah masyarakat yang terpapar tuberkulosis, baik penderita ataupun bukan penderita. Indicator yang ditetapkan adalah paparan infeksi tuberkulosis pada masyarakat tersebut. Comparation yang ditetapkan adalah pengetahuan tentang penyakit tuberkulosis. Outcome yang diukur adalah perilaku masyarakat dalam mencari fasilitas kesehatan untuk penanganan penyakit tuberkulosis, serta study design yang ditetapkan adalah penelitian deskriptif.

Proses seleksi artikel dimulai dengan proses scanning, yaitu dengan memasukkan kata kunci ke dalam mesin pencari dengan bantuan boolean operator, yaitu "community" OR "adult" AND , "knowledge" AND "behavior" OR "health seeking" OR "attitude" OR "practice" AND "tuberculosis". Proses scanning dilakukan dengan mesin pencari Science
Direct, Scopus, dan Ebsco Host. Proses selanjutnya yang dilakukan oleh peneliti adalah melakukan skimming. Proses skimming dilakukan dengan cara mencermati judul dan membaca abstrak dari setiap artikel dengan seksama. Bila dari gambaran abstrak dirasa artikel tersebut relevan dengan tujuan penelitian, maka peneliti membaca fulltext dari artikel tersebut dan memberikan highlight bagianbagian yang dianggap perlu. Langkah selanjutnya adalah menetapkan artikelartikel yang terpilih dengan menggunakan kriteria inklusi sebagai patokan. Selanjutnya peneliti melakukan mapping dengan cara memetakan informasi yang telah di-highlight untuk membentuk sebuah pola data beserta sumber sitasinya. Analisis data dilakukan dengan metode narrative review dengan cara menampilkannya dalam tabel.

\section{HASIL}

Pada awal pencarian, didapatkan sejumlah 328 artikel dari mesin pencari, dengan rincian 258 artikel ditemukan melalui Scince Direct, 38 artikel dari Scopus dan 32 artikel dari Ebsco Host. Sejumlah 296 artikel dieksklusi karena tidak sesuai dengan tujuan penelitian. Sejumlah 10 artikel dieksklusi karena tidak dapat diunduh dan tidak tersedia dalam bentuk fulltext. Sejumlah empat belas artikel fulltext dieksklusi karena tidak sesuai dengan kriteria inklusi. Pada akhirnya terdapat delapan artikel yang dianalisis lebih lanjut dalam penelitian ini. Alur pencarian artikel disajikan pada gambar 1 . 


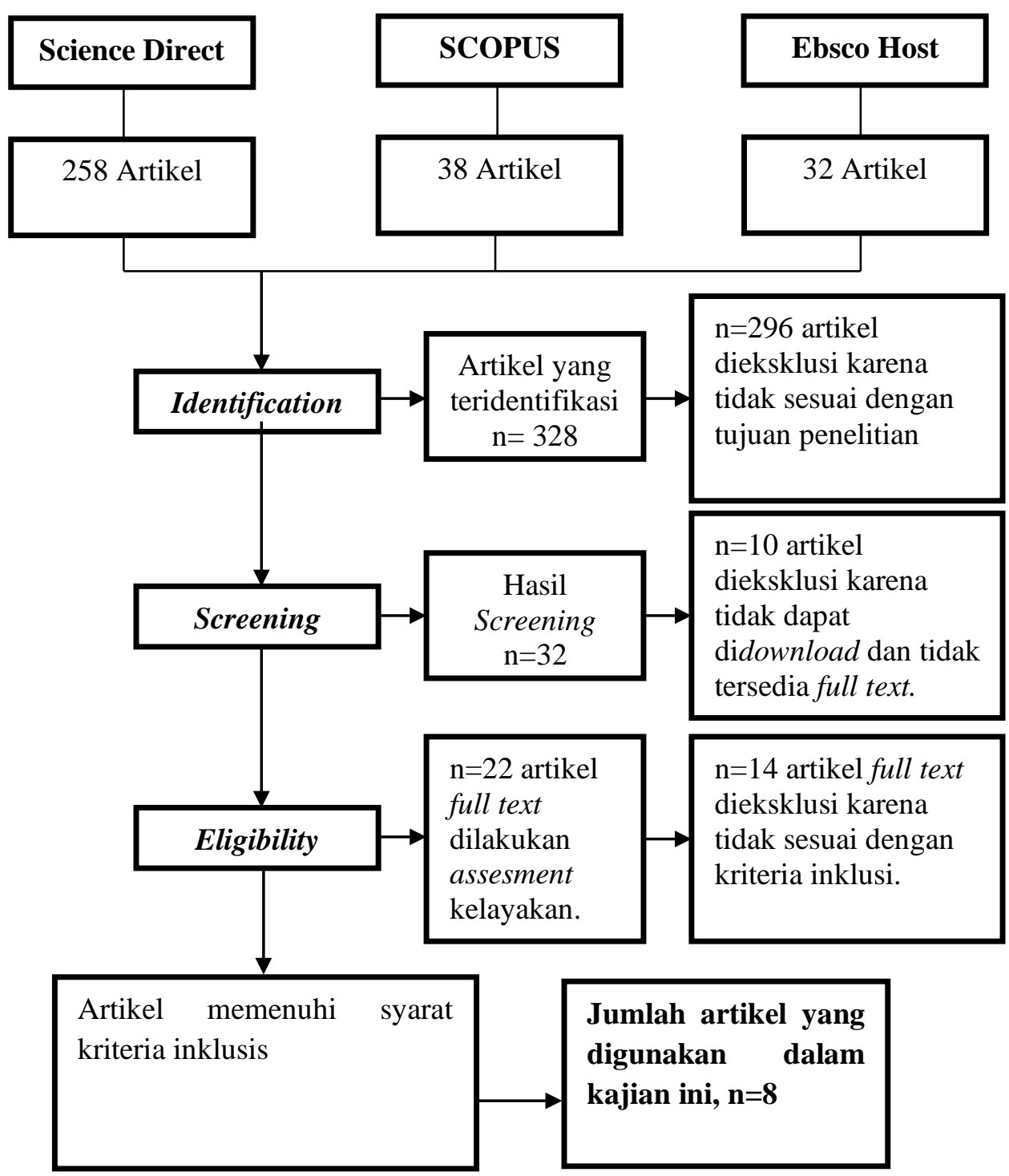

Gambar 1. Alur pencarian pustaka

Hasil penelitian menunjukkan bahwa pengetahuan responden tentang penyebab TBC adalah bakteri, stress, dan emosi (Ali et al., 2019; Datiko, Habte, Jerene, \& Suarez, 2018; Luba, Tang, Liu, Gebremedhin, Kisasi \& Feng, 2019; Tolossa, Medhin, \& Legesse, 2014). Pengetahuan tentang tanda dan gejala tuberkulosis bervariasi antara lain batuk, batuk selama 2-3 minggu, batuk persisten, nyeri dada, demam, penurunan berat badan, nafsu makan buruk, keringat di malam hari, dahak bercampur darah, sesak napas, kelelahan, atau pembengkakan kelenjar tubuh (Datiko et al., 2018; Khan, Shaikh, \& Baig, 2020; Luba et al., 2019; Tolossa, Medhin, \& Legesse, 2014). Pengetahuan tentang cara penularan TBC sangat bervariasi. Berbagai cara penularan TBC yang dipahami adalah melalui batuk 
atau bersin, makanan yang terkontaminasi, berbagi makanan dengan penderita tuberkulosis, air dan makanan yang tidak bersih, berbagi peralatan makan dengan penderita TBC, menyentuh penderita, berjabat tangan, dan melakukan hubungan seks dengan penderita TBC (Ali et al., 2019; Datiko et al., 2018; Khan, Shaikh, \& Baig, 2020; Luba et al., 2019; Sreeramaredd, Kumar \& Arokiasamy, 2013. Responden mengetahui bahwa TBC adalah penyakit yang dapat disembuhkan (Ali et al., 2019; Datiko et al., 2018; Sreeramaredd, Kumar, \& Arokiasamy, 2013). Pengetahuan masyarakat tentang pencegahan penularan TBC meliputi menghindari berbagi peralatan makanan, menghindari berjabat tangan, mencuci tangan setelah menyentuh barang-barang di tempat umum, mempertahankan nutrisi yang baik, obat-obatan dan vaksinasi BCG, berdoa dan menutup jendela rumah (Luba et al., 2019)

Terdapat perbedaan sikap dan perilaku masyarakat dalam mencari pelayanan kesehatan untuk mendapatkan penanganan penyakit TBC. Sebagian masyarakat merahasiakan kepada tetangga apabila ada anggota keluarganya yang menderita TBC (Sreeramaredd, Kumar, \& Arokiasamy, 2013). Sebagian masyarakat mencari pelayanan kesehatan untuk mendapatkan penanganan TBC. Pelayanan kesehatan yang umumnya didatangi oleh masyarakat bersifat tradisional maupun modern. Beberapa bentuk layanan kesehatan yang teridentifikasi digunakan oleh masyarakat untuk berobat meliputi fasilitas kesehatan publik milik pemerintah, fasilitas kesehatan swasta, dokter praktik, membeli obat secara langsung ke apotek, dan meminta bantuan kepada tabib tradisional (Datiko et al., 2018; Khan, Shaikh, \& Baig, 2020; Tolossa, Medhin, \& Legesse., 2014; Samal, \& Dehuri, 2017; Mushtaq et al.,
2011). Rangkuman hasil kajian ini ditampilkan selengkapnya pada tabel 1 .

\section{PEMBAHASAN}

\section{Pengetahuan Masyarakat tentang Tuberkulosis}

Pengetahuan mengenai TBC adalah sejauh mana masyarakat mengetahui tentang penyebab, tanda dan gejala, cara penularan, dan cara pencegahan penularan. Mayoritas artikel penelitian yang digunakan dalam kajian pustaka ini menyebutkan bahwa semua responden pernah mendengar tentang penyakit TBC, tetapi mempunyai pengetahuan yang bervariasi tentang TBC. Hal ini dibuktikan dari penelitian yang dilakukan di kota Shiline, Ethiopia, menunjukkan bahwa sebanyak $94,9 \%$ responden mengatakan pernah mendengar tentang TBC (Tolossa, Medhin, \& Legesse, 2014). Penelitian lain yang dilakukan di India pada tahun 2013, yang mengungkapkan bahwa sebanyak $89,3 \%$ responden pernah mendengar tentang TBC (Sreeramareddy, Harsha Kumar, \& Arokiasamy, 2013). Selain itu penelitian di Pakistan mengungkapkan bahwa hampir semua responden (99\%) melaporkan pernah mendengar tentang penyakit TBC (Khan, Shaikh, \& Baig, 2020). Responden mungkin mendengar informasi tentang TBC dari tetangga, petugas kesehatan saat penyuluhan kesehatan, melalui sarana telekomunikasi dan lain sebagainya. Hal ini diperkuat oleh penelitian yang dilakukan di Puskesmas Sepatan, Tengerang menyebutkan bahwa semua responden mengatakan sudah mendengar tentang TBC paru karena terdapat anggota keluarga yang sedang menderita penyakit paru-paru, dan ada juga yang mengetahui karena diberitahu oleh keluarga, tetangga dan petugas kesehatan (Manulu \& Sukana, 2011). 
Tabel 1. Matriks Sintesis Artikel

\begin{tabular}{|c|c|c|c|c|}
\hline No & Penulis dan Tahun & Judul Artikel & Metode & Temuan \\
\hline 1. & $\begin{array}{l}\text { Syed Mustafa Ali, Naveed } \\
\text { Anjum, Muhammad Ishaq, } \\
\text { Farah Naureen, Arif Noor, } \\
\text { Aamna Rashid, Syed } \\
\text { Muslim Abbas, Kerri Viney. } \\
\text { (2019) }\end{array}$ & $\begin{array}{l}\text { Community Knowledge about } \\
\text { Tuberculosis and Perception } \\
\text { about Tuberculosis Associated } \\
\text { Stigma in Pakistan }\end{array}$ & $\begin{array}{l}\text { Survei cross- } \\
\text { sectional. }\end{array}$ & $\begin{array}{l}\text { Mayoritas responden menyadari bahwa TBC adalah penyakit yang dapat } \\
\text { disembuhkan }(87 \% \text {; } \mathrm{n}=159) \text { dan menyebar melalui batuk }(91 \% ; \mathrm{n}=167) \text {. } \\
\text { Sebagian responden menyatakan bahwa TBC ditularkan melalui makanan } \\
\text { yang terkontaminasi }(73 \% \text {; } \mathrm{n}=134) \text {, berbagi makanan dengan penderita } \\
\text { tuberkulosis }(55 \% \text {; } \mathrm{n}=100) \text {, air dan makanan yang tidak bersih }(62 \% ; \mathrm{n}=114) \text {, } \\
\text { berbagi peralatan makan dengan penderita tuberkulosis }(53 \% ; \mathrm{n}=96) \text {, } \\
\text { menyentuh penderita }(33 \% \text {; }=61) \text {, dan dengan melakukan hubungan seks } \\
\text { dengan penderita }(51 \% ; \mathrm{n}=93) \text {. Setengah dari responden }(50 \% ; \mathrm{n}=91) \\
\text { mengatakan bahwa stres dan emosional adalah penyebab tuberkulosis dan } \\
30 \% \text { responden ( } \mathrm{n}=54) \text { berpendapat bahwa TBC menyebabkan infertilitas. } \\
\text { Mayoritas resoponden menyadari bahwa TBC menyebar melalui batuk dan } \\
\text { dapat disembuhkan. Namun, walaupun banyak responden memahami cara } \\
\text { penularan tuberkulosis yang benar, sebagian besar responden memiliki } \\
\text { pengetahuan yang salah tentang penularan tuberkulosis, misalnya masih ada } \\
\text { responden yang menyatakan bahwa tuberkulosis dapat ditularkan dengan } \\
\text { menyentuh penderita tuberkulosis, melalui air dan makanan yang tidak bersih. } \\
\text { Sebanyak 53\% ( } \mathrm{n}=96) \text { responden menganggap berbagi peralatan makanan } \\
\text { dengan penderita sebagai mode potensial penularan TBC. }\end{array}$ \\
\hline 2. & $\begin{array}{l}\text { Daniel G. Datiko, Dereje } \\
\text { Habte, Degu Jerene, Pedro } \\
\text { Suarez. (2018) }\end{array}$ & $\begin{array}{l}\text { Knowledge, Attitudes, and } \\
\text { Practices related to Tuberculosis } \\
\text { among the General Population of } \\
\text { Ethiopia: Findings from a } \\
\text { National Cross-Sectional Survey. }\end{array}$ & $\begin{array}{l}\text { Survei Knowlegde, } \\
\text { Attitude, and Practice } \\
(\text { KAP) Tuberculosis. }\end{array}$ & $\begin{array}{l}\text { Sebagian besar responden }(95,5 \%) \text { pernah mendengar tentang TBC namun } \\
\text { hanya } 25,8 \% \text { mengetahui bahwa TBC disebabkan oleh bakteri. Sebanyak } 47 \% \\
\text { responden tidak tahu penyebab TBC. Cara penularan TB yang disebutkan } \\
\text { responden adalah batuk atau bersin }(70,4 \%) \text {. gejala yang paling umum adalah } \\
\text { batuk pada }(85,5 \%) \text {, nyeri dada }(17,2 \%) \text {, demam }(17,1 \%) \text {, dan sebanyak } \\
67,6 \% \text { responden menyebutkan gejala lain TBC yakni; penurunan berat badan, } \\
\text { nafsu makan buruk, keringat di malam hari, dahak bercampur darah, sesak } \\
\text { napas, kelelahan, atau pembengkakan kelenjar tubuh. sebagian besar } \\
\text { responden }(75,9 \%) \text { mengetahui bahwa siapa pun bisa menderita TBC. Organ } \\
\text { tubuh yang terkena TBC adalah paru-paru }(80 \%) \text { dan tulang }(23,3 \%) \text {. }\end{array}$ \\
\hline
\end{tabular}




\begin{tabular}{|c|c|c|c|c|}
\hline No & Penulis dan Tahun & Judul Artikel & Metode & Temuan \\
\hline & & & & $\begin{array}{l}\text { sebagian besar responden }(85,3 \%) \text {, tahu bahwa TBC dapat disembuhkan } \\
\text { dengan minum obat selama } 6-9 \text { bulan. sedangkan pada variabel praktik terkait } \\
\text { TBC, sebanyak } 96 \% \text { melaporkan akan pergi ke fasilitas kesehatan publik jika } \\
\text { mengalami gejala TBC, } 13 \% \text { memilih fasilitas swasta, } 3 \% \text { apotek, dan } 1 \% \\
\text { tabib tradisional. }\end{array}$ \\
\hline 3. & $\begin{array}{l}\text { Adeela Khan, Babar } \\
\text { Tasneem Shaikh, Mirza } \\
\text { Amir Baig. (2020) }\end{array}$ & $\begin{array}{l}\text { Knowledge, Awareness, and } \\
\text { Health-Seeking Behaviour } \\
\text { regarding Tuberculosis in a Rural } \\
\text { District of Khyber Pakhtunkhwa, } \\
\text { Pakistan }\end{array}$ & $\begin{array}{l}\text { Wawancara dengan } \\
\text { menggunakan } \\
\text { kuesioner terstruktur. }\end{array}$ & $\begin{array}{l}\text { Hampir semua responden mengatakan pernah mendengar tentang TBC. Pada } \\
\text { variabel pengetahuan tentang gejala TBC, sebanyak } 39 \% \text { responden } \\
\text { menyebutkan batuk bercampur darah, } 24 \% \text { responden menyebutkan batuk } \\
\text { dengan demam, hanya } 7 \% \text { responden yang menyebutkan batuk selama } 2-3 \\
\text { minggu (klasik gejala tuberkulosis). Pengetahuan mengenai penyebab TBC } \\
\text { dimana } 22 \% \text { responden menyebutkan bahwa TBC ditularkan melalui udara } \\
\text { ketika penderita batuk atau bersin, dan } 12 \% \text { menyebutkan makan dari piring } \\
\text { yang sama sebagai mode penularan penyakit, dan sebanyak } 18 \% \text { responden } \\
\text { mengatakan tidak tahu tentang cara penularan TBC. Pada pengetahuan tentang } \\
\text { pencegahan tuberkulosis, jawaban yang diperoleh dari responden bervariasi } \\
\text { tanggapan yang diberikan dimana sebanyak } 19 \% \text { responden menyatakan } \\
\text { bahwa penyebaran TBC dapat dicegah dengan menutup mulut saat batuk dan } \\
\text { bersin, } 18 \% \text { responden mengatakan dengan memberikan nutrisi yang baik, } \\
13 \% \text { responden mengatakan akan menghindari makan dari piring yang sama } \\
\text { dengan penderita, dan } 6 \% \text { responden mengatakan tidak akan berbagi tempat } \\
\text { tidur dengan penderita, } 14 \% \text { responden mengaku tidak tahu banyak tentang } \\
\text { pencegahan penularan tuberkulosis. Pada variabel perilaku, sebanyak } 45 \% \\
\text { responden mengatakan akan mengunjungi fasilitas kesehatan pemerintah } \\
\text { terdekat apabila timbul tanda dan gejala TBC, } 41 \% \text { responden mengatakan } \\
\text { akan berkonsultasi dengan dokter swasta dan sisanya mengatakan akan } \\
\text { berkonsultasi dengan keluarga untuk meminta saran dan pendapat. }\end{array}$ \\
\hline
\end{tabular}




\begin{tabular}{|c|c|c|c|c|}
\hline No & Penulis dan Tahun & Judul Artikel & Metode & Temuan \\
\hline 4. & $\begin{array}{l}\text { Chandrashekhar T. } \\
\text { Sreeramaredd, H. N. Harsha } \\
\text { Kumar, John T. Arokiasamy } \\
\text { (2013) }\end{array}$ & $\begin{array}{l}\text { Prevalence of Self-Reported } \\
\text { Tuberculosis, Knowledge about } \\
\text { Tuberculosis Transmission and } \\
\text { Its Determinants among Adults in } \\
\text { India: Results from a Nation-wide } \\
\text { Cross-sectional Household } \\
\text { Survey. }\end{array}$ & $\begin{array}{l}\text { Menggunakan survei, } \\
\text { wawancara dan } \\
\text { kuesioner }\end{array}$ & $\begin{array}{l}\text { Sebanyak } 89,3 \% \text { responden pernah mendengar tentang TBC. Sebanyak } 26,8 \% \\
\text { responden menjawab tidak tahu tentang cara penularan TBC dan } 55,5 \% \\
\text { responden mengetahui tentang cara penularan TBC yakni melalui batuk atau } \\
\text { bersin. Masih ditemukan kesalahpahaman tentang cara penularan TBC yakni } \\
\text { melalui makanan }(32,4 \%) \text {, berbagi peralatan dengan penderita }(18,2 \%) \text {, dan } \\
\text { menyentuh pasien TBC (12,3\%). Sebanyak } 83,5 \% \text { responden mengatakan } \\
\text { bahwa TBC dapat disembuhkan, sedangkan } 15,6 \% \text { responden mengatakan } \\
\text { akan merahasiakan kepada tetangga apabila ada anggota keluarganya yang } \\
\text { menderita TBC. }\end{array}$ \\
\hline
\end{tabular}

5. Daniel Tolossa, Girmay

Medhin, Mengistu Legesse. (2014)

Community Knowledge, Attitude,

and Practices towards

Tuberculosis in Shinile Town,

Somali Tegional State, Eastern

Ethiopia: A Cross-sectional Study
Desain penelitian cross sectional, kuisioner.
Sebanyak 94,9\% responden mengatakan pernah mendengar tentang TBC, hanya $22,9 \%$ yang mengetahui bahwa TBC disebabkan oleh bakteri. Sebanyak $80 \%$ responden menyadari bahwa TBC dapat ditularkan dari pasien ke orang lain dan 79,3\% mengetahui bahwa penularan TBC dapat dicegah. Sebanyak $72,4 \%$ responden mengatakan bahwa batuk persistensi adalah gejala TBC yang paling umum dan obat modern yang digunakan di fasilitas kesehatan. Sebanyak 71,0\% responden mengatakan akan mencari pengobatan di fasilitas kesehatan jika menyadari bahwa telah memiliki gejala yang berkaitan dengan TBC. Sebanyak 55,4\% menganggap tuberkulosis sebagai penyakit yang sangat serius dan 69,3\% akan mengalami ketakutan jika menderita TBC.

\section{Janmejaya Samal, Ranjit Kumar Dehuri. (2017)}

\section{Impact of a Structured}

Tuberculosis Awareness Strategy on the Knowledge and Behaviour of the Families in a Slum Area in Chhattisgarh, India
Kuesioner survei sebelum dan setelah pelaksanaan intervensi.
Terjadi peningkatan level pengetahuan tentang TBC dan perilaku mencari fasilitas kesehatan untuk pengobatan TBC setelah pelaksanaan pelatihan dan pendidikan tentang TBC. 


\begin{tabular}{|c|c|c|c|c|}
\hline No & Penulis dan Tahun & Judul Artikel & Metode & Temuan \\
\hline 7. & $\begin{array}{l}\text { Tegene Regassa Luba, } \\
\text { Shangfeng Tang, Qiaoyan } \\
\text { Liu, Simon Afewerki } \\
\text { Gebremedhin, Matiko D. } \\
\text { Kisasi dan Zhanchun Feng. } \\
\text { (2019) }\end{array}$ & $\begin{array}{l}\text { Knowledge, Attitude and } \\
\text { Associated Factors towards } \\
\text { Tuberculosis in Lesotho: A } \\
\text { Population-Based Study }\end{array}$ & $\begin{array}{l}\text { Menggunakan desain } \\
\text { studi Analisis cross- } \\
\text { sectional dilakukan } \\
\text { dengan teknik } \\
\text { wawancara. }\end{array}$ & $\begin{array}{l}\text { Sebagian besar responden mengetahui cara penularan TBC yang benar yakni } \\
\text { melalui udara ketika batuk atau bersin. Kesalahpahaman tentang cara } \\
\text { penularan TBC yaitu bahwa TBC dapat ditularkan melalui berbagi peralatan, } \\
\text { kontak seksual, makan di piring yang sama dengan penderita, berjabat tangan } \\
\text { dengan penderita dan menyentuh barang-barang di tempat umum. Hanya } \\
11,5 \% \text { responden menyebutkan bahwa TBC disebabkan oleh bakteri } \\
\text { Mycobacterium tuberculosis. Sebanyak } 26,3 \% \text { responden menyebutkan bahwa } \\
\text { TBC disebabkan karena merokok, } 13,2 \% \text { responden mengatakan karena suhu } \\
\text { dingin dan } 44,3 \% \text { responden mengatakan TBC disebabkan oleh debu/polusi. } \\
\text { Pengetahuan tentang tanda dan gejala TBC rendah meliputi batuk selama } \\
\text { beberapa minggu ( } 55,5 \% \text { responden), penurunan berat badan ( } 41,9 \% \\
\text { responden), berkeringat di malam hari ( } 38,1 \% \text { responden), kehilangan nafsu } \\
\text { makan ( } 22,8 \% \text { responden), nyeri di dada atau punggung (7,2\% responden) dan } \\
\text { demam persisten ( } 7,1 \% \text { responden). Responden menyebutkan menghindari } \\
\text { berbagi peralatan makanan, menghindari berjabat tangan, mencuci tangan } \\
\text { setelah menyentuh barang-barang di tempat umum, mempertahankan nutrisi } \\
\text { yang baik, obat-obatan dan vaksinasi BCG, berdoa dan menutup jendela } \\
\text { rumah. }\end{array}$ \\
\hline 8. & $\begin{array}{l}\text { Muhammad Umair Mushtaq, } \\
\text { Ubeera Shahid, Hussain } \\
\text { Muhammad Abdullah, } \\
\text { Anum Saeed, Fatima Omer, } \\
\text { Mushtaq Ahmad Shad, Arif } \\
\text { Mahmood Siddiqui, Javed } \\
\text { Akram. (2011) }\end{array}$ & $\begin{array}{l}\text { Urban-Rural Inequities in } \\
\text { Knowledge, Attitudes and } \\
\text { Practices regarding Tuberculosis } \\
\text { in Two Districts of Pakistan's } \\
\text { Punjab Province }\end{array}$ & $\begin{array}{l}\text { Menggunakan desain } \\
\text { studi analisis cross- } \\
\text { sectional dilakukan } \\
\text { dengan teknik } \\
\text { wawancara. }\end{array}$ & $\begin{array}{l}\text { Responden yang tinggal di daerah pedesaan mempunyai pengetahuan yang } \\
\text { buruk tentang TBC. Responden yang tinggal di daerah perkotaan lebih banyak } \\
\text { mengetahui tentang gejala, cara penularan, cara pencegahan, durasi } \\
\text { pengobatan TBC, dan segera mencari fasiltas kesehatan jika mempunyai } \\
\text { gejala TBC. Responden yang tinggal di daerah perkotaan lebih merasa malu } \\
\text { jika menderita TBC, tetapi masyarakat selalu memberi dukungan jika ada } \\
\text { anggota keluarga yang menderita TBC. }\end{array}$ \\
\hline
\end{tabular}


Penelitian yang dilakukan pada populasi umum di Leshoto, mengungkapkan bahwa hanya $11,5 \%$ responden, menyebutkan bahwa TBC disebabkan oleh bakteri Mycobacterium tuberculosis. Selain itu, sebanyak 26,3\% menyebutkan bahwa TBC disebabkan karena merokok, $13,2 \%$ responden mengatakan karena suhu dingin dan $44,3 \%$ responden mengatakan TBC disebabkan oleh debu/polusi (Luba et al., 2019). Penelitian lain yang dilakukan di Pakistan pada masyarakat mengungkapkan bahwa setengah dari responden mengatakan stress emosional adalah penyebab TBC (Ali et al., 2019). Penelitian yang dilakukan di Kabupaten Tanah Datar, Sumatra Barat yang menyebutkan bahwa persepsi masyarakat tentang penyebab penyakit TBC adalah karena guna-guna atau magic (perbuatan manusia dan setan), dan karena faktor keturunan (dari orang tua), kebiasaan keluar malam (duduk di kedai) atau kena angin malam, merokok, minum kopi dan alkhohol, lingkungan rumah yang kurang bersih, bekerja di lingkungan yang banyak mengeluarkan debu, bekerja terlalu berat dan makan tidak teratur (Media, 2011).

Batuk sebagai tanda dan gejala tuberkulosis yang paling umum disebutkan oleh responden. Hal ini dapat dilihat dari hasil penelitian yang dilakukan pada populasi umum di Leshoto, menyebutkan bahwa gejala tuberkulosis adalah batuk selama beberapa minggu $(55,5 \%$ responden), penurunan berat badan $(41,9 \%$ responden), berkeringat di malam hari $(38,1 \%$ responden), kehilangan nafsu makan (22,8\% responden), nyeri dada atau punggung $(7,2 \%$ responden) dan demam persisten (7,1\% responden) (Luba et al., 2019). Hasil penelitian yang dilakukan di Ethiopia menyebutkan bahwa gejala yang paling umum adalah batuk pada $(85,5 \%)$, nyeri dada $(17,2 \%)$, demam $(17,1 \%)$, dan
$67,6 \%$ responden menyebutkan gejala lainnya seperti penurunan berat badan, nafsu makan buruk, keringat di malam hari, dahak bercampur darah, sesak napas, kelelahan, atau pembengkakan kelenjar tubuh (Datiko et al., 2019). Hasil kajian pustaka yang dilakukan oleh peneliti menunjukan bahwa cara penularan tuberkulosis adalah melalui batuk dan bersin. Penelitian yang dilakukan di India, mengungkapkan bahwa sebanyak 55,5\% responden mengetahui tentang cara penularan TBC yakni melalui batuk atau bersin. (Sreeramareddy et al., 2013). Penelitian diatas sama dengan yang dilakukan di Ethiopia, yang mengungkapkan bahwa cara penularan TBC yang disebutkan oleh responden adalah batuk atau bersin (Datiko et al., 2019).

Masih ditemukan kesalahpahaman tentang cara penularan TBC yang sebutkan oleh responden. Berdasarkan penelitian yang dilakukan di Pakistan, menunjukkan bahwa masyarakat menyatakan TBC dapat ditularkan melalui makanan yang terkontaminasi $(73 \%)$, berbagi makanan (55\%), air dan makanan yang tidak bersih (62\%), berbagi peralatan makan (53\%), menyentuh penderita TBC (33\%), dan dengan melakukan hubungan seks dengan orang dengan TBC (51\%) (Ali et al., 2019). Penelitian ini sama dengan yang dilakukan di India yang mengungkapkan bahwa cara penularan TBC yakni melalui makanan $(32,4 \%)$, berbagi peralatan dengan penderita $(18,2 \%)$, dan menyentuh pasien tuberkulosis (12,3\%) (Sreeramareddy et al., 2013). Pada pengetahuan tentang pencegahan TBC, berbagai jawaban dan tanggapan yang diperoleh dari responden penelitian yang dilakukan di Pakistan, menyebutkan bahwa sebanyak $19 \%$ responden menyatakan bahwa penyebaran TBC dapat dicegah dengan menutup mulut saat batuk dan 
bersin, 18\% responden mengatakan dengan memberikan nutrisi yang baik, $13 \%$ responden mengatakan akan menghindari makan dari piring yang sama dengan penderita, dan $6 \%$ responden mengatakan tidak akan berbagi tempat tidur dengan penderita, $14 \%$ responden mengaku tidak tahu banyak tentang pencegahan penularan tuberkulosis (Khan et al., 2020). Sedangkan penelitian yang dilakukan di Leshoto menyebutkan bahwa pencegahan penularan TBC yang disebutkan oleh responden yakni; menghindari berbagi peralatan makanan, menghindari berjabat tangan, mencuci tangan setelah menyentuh barang-barang di tempat umum, mempertahankan nutrisi yang baik, obatobatan dan vaksinasi BCG, berdoa dan menutup jendela rumah (Luba et al., 2019).

Pengetahuan yang buruk dan kesalahpahaman tentang penyakit TBC, tanda dan gejala, cara penularan serta cara pencegahan penyakit TBC diakibatkan karena kurangnya informasi kesehatan yang diperoleh masyarakat tentang penyakit tuberkulosis. Untuk meningkatkan pengetahuan masyarakat tentang penyakit TBC dapat dilakukan dengan cara memberikan pendidikan penyuluhan dan pelatihan kesehatan terkait tuberkulosis oleh tenaga medis kepada masyarakat. Penelitian yang dilakukan di India, mengungkapkan bahwa terjadi peningkatan level pengetahuan tentang tuberkulosis dan perilaku mencari fasilitas kesehatan untuk pengobatan TBC setelah pelaksanaan pelatihan dan pendidikan tentang TBC (Samal \& Dehuri, 2017).

\section{Perilaku Mencari Fasilitas Kesehatan dalam Penanganan Tuberkulosis}

Perilaku pencarian kesehatan oleh masyarakat yang ditemukan dalam kajian pustaka ini menunjukan masih ada masyarakat yang tidak segera mencari fasilitas kesehatan untuk mendapatkan perawatan dan pengobatan. Masih ditemukan masyarakat yang pergi membeli obat di apotek dan pergi ke dukun/tabib tradisional untuk mendapatkan pengobatan TBC (Datiko et al., 2019). Penelitian lain menyebutkan bahwa responden mengatakan akan mengunjungi fasilitas kesehatan pemerintah terdekat apabila timbul tanda dan gejala TBC, berkonsultasi dengan dokter swasta dan akan berkonsultasi dengan keluarga untuk meminta saran dan pendapatnya (Khan et al., 2020). Keterlambatan pencarian fasilitas kesahatan terutama dipengaruhi oleh ketidaktahuan gejala penyakit TBC (Dewi et al., 2016). Perilaku pencarian fasilitas kesehatan untuk mendapatkan pengobatan TBC yang baik dan benar merupakan salah satu cara untuk mencegah penularan tuberkulosis, mencegah agar penyakit tuberkulosis yang diderita tidak semakin parah dan mencegah kematian. Penelitian yang dilakukan di distrik Somalia, Ethiopia, menunjukkan bahwa sebesar $71,0 \%$ responden mengatakan akan mencari pengobatan di fasilitas kesehatan jika orang akan menyadari memiliki gejala yang berkaitan dengan TBC (Tolossa et al., 2014). Hal ini didukung oleh penelitian lain yang juga dilakukan di Ethiopia, dengan hasil penelitiannya menunjukan bahwa dari 2.483 peserta, (96\%) responden melaporkan akan pergi ke fasilitas kesehatan umum jika mengalami gejala TBC (Datiko et al., 2019).

Perilaku masyarakat segera mencari fasilitas kesehatan bermanfaat untuk mendapatkan perawatan dan pengobatan sehingga TBC yang diderita oleh masyarakat dapat disembuhkan yang berdampak agar penyakit ini tidak tertular kepada orang lain dan mencegah agar penyakit TBC yang diderita tidak semakin parah yang dapat mengakibatkan kematian. Penelitian yang dilakukan di Nigeria menyebutkan bahwa orang yang percaya 
bahwa penyakit TBC yang disebabkan oleh kuman biasanya mencari perawatan kesehatan di fasilitas kesehatan yang resmi, sedangkan yang percaya bahwa TBC disebabkan oleh kekuatan supranatural, seperti kutukan leluhur dan sihir, biasanya mencari bantuan pada ahli jamu atau pengobatan tradisional (Kusimo et al., 2015). Berbagai alasan yang membuat Perilaku masyarakat dalam pencarian pelayanan kesehatan untuk mendapatkan perawatan dan pengobatan bagi keluarganya yang menderita penyakit TBC. Penelitian yang di Puskesmas Sepatan, Tengerang mengungkapkan bahwa sebagian besar masyarakat menyatakan menggunakan tempat pelayanan di Puskesmas untuk berobat. Namun dalam ketaatan minum obat selama enam bulan tidak dilakukan dengan sebaikbaiknya dengan alasan karena sudah merasa sembuh, terlalu lama makan obat, sehingga keluarga pun putus asa dalam berobat dan berpindah-pindah dengan alasan tidak sembuh-sembuh. Ditambah lagi dengan keadaan sosial ekonomi keluarga yang rendah tidak dapat berobat, karena tidak memiliki biaya transportasi untuk berobat ke Puskesmas, karena jarak antara rumah dengan Puskesmas yang cukup jauh (Manulu \& Sukana, 2011).

\section{KESIMPULAN DAN SARAN}

Masih terjadi kesalahpahaman tentang penyebab penyakit TBC di kalangan masyarakat yakni stres dan emosional. Masih ditemukan responden yang menggunakan pengobatan alternatif/tradisional. Masih ditemukan masyarakat yang membeli obat di apotek, berobat ke dukun/tabib tradisional, dan tidak berkonsultasi kesehatan dengan petugas medis tentang sakit atau penyakit yang diderita. Masyarakat lebih mmilih untuk berkonsultasi pada keluarga. Oleh karena itu perlunya edukasi kepada masyarakat untuk meningkatkan pengetahuan masyarakat terkait TBC dan perilaku segera mencari fasilitas kesehatan dalam penanganan penyakit TBC.

Kelemahan kajian pustaka ini adalah tidak dilakukannya critical appraisal terhadap artikel yang terpilih, sehingga masih membuka peluang untuk tercampurnya antara artikel yang berkualitas tinggi dan rendah. Meskipun terdapat kelemahan dari proses telaah yang dilakukan, namun hasil telaah ini dapat digunakan sebagai dasar perencanaan untuk menyusun program edukasi masyarakat tentang infeksi TBC di waktu mendatang. Perlu dilakukan kajian lebih lanjut tentang faktor yang mendasari perilaku masyarakat dalam mencari fasilitas kesehatan dalam penanganan tuberkulosis.

\section{UCAPAN TERIMA KASIH}

Peneliti mengucapkan banyak terimakasih kepada Ibu Ns. Niken Safitri DK, S.Kep., M.Si.Med dan Bapak Dr.Luky Dwiantoro, S.Kp., M.Kep yang sudah memberikan masukan dan evaluasi yang membangun, dan terimakasih kepada semua pihak yang membantu dari awal sampai akhir pembuatan kajian pustaka ini.

\section{DAFTAR PUSTAKA}

Agustina, S., \& Wahjuni, C. U. (2017). Pengetahuan dan tindakan pencegahan penularan penyakit tuberkulosa paru pada keluarga kontak serumah. Jurnal Berkala Epidemiologi, 5(1), 85-94. doi: 10.20473/jbe.v5i1

Ali, S. M., Anjum, N., Ishaq, M., Naureen, F., Noor, A., Rashid, A., ... Viney, K. (2019). Community knowledge about tuberculosis and perception about tuberculosis-associated stigma in Pakistan. Multidiscplinary Digital 
Publishing Institute (MDPI), 9(9), 112. doi: $10.3390 /$ soc 9010009

Datiko, D. G., Habte, D., Jerene, D., \& Suarez, P. (2019). Knowledge, attitudes, and practices related to tuberculosis among the general population of Ethiopia: Findings from a national cross-sectional survey. PLoS ONE, 14(10), 1-16.

Dewi, C., Barclay, L., Passey, M., \& Wilson, S. (2016). Improving knowledge and behaviours related to the cause, transmission and prevention of tuberculosis and early case detection: A descriptive study of community led Tuberculosis program in Flores, Indonesia. BMC Public Health, 16(1), 1-12. doi: 10.1186/s12889-016-3448-4

Hidayat, D ., Setiawati, E. P., \& Soeroto, A. Y. (2017). Gambaran perilaku pencarian pengobatan pasien tuberkulosis di Kota Bandung. Jurnal Sistem Kesehatan, 3(2), 6572.

Khan, A., Shaikh, B. T., \& Baig, M. A. (2020). Knowledge, awareness, and health-seeking behaviour regarding tuberculosis in a rural district of Khyber Pakhtunkhwa, Pakistan. BioMed Research International, 1-6.

Kusimo, O., Olukolade, R., Hassan, A., Okwuonye, L., Osinowo, K., Ogbuji, Q., ... Ladipo, O. A. (2015). Perceptions of community members on tuberculosis and its effect on health-seeking behavior in Nigeria. International Journal of Mycobacteriology, 4(6).

Luba, T. R., Tang, S., Liu, Q., Gebremedhin, S. A., Kisasi, M. D., \& Feng, Z. (2019). Knowledge, attitude and associated factors towards tuberculosis in Lesotho: A population based study. BMC Infectious Diseases, 19(1), 1-11. doi: 10.1186/s12879-019-3688-x

Manulu, H. S. P., \& Sukana, B. (2011). Aspek pengetahuan sikap dan perilaku masyarakat kaitannya dengan penyakit tuberculosis paru. Media Litbang Kesehatan, 21(1), 39-46.

Marlina, I. (2018). Infodatin (pusat data dan informasi kesehatan). Kementrian Kesehatan RI. Jakarta, Indonesia: Kementrian Kesehatan RI. doi: 2442-7659

Mbuthia, G. W., Olungah, C. O., \& Ondicho, T. G. (2018). Knowledge and perceptions of tuberculosis among patients in a pastoralist community in Kenya: A qualitative study. Pan African Medical Journal, 30, 1-6.

Media, Y. (2011). Pengetahuan, sikap dan perilaku masyarakat tentang penyakit tuberkulosis paru di kecamatan Sungai Tarab, Kabupaten Tanah Datar Propinsi Sumatera Barat. Media Litbang Kesehatan, 21(2), 82-88. doi: 10.22435/mpk.v21i2Jun.108.

Mursyaf, N. A. S., Nurdiyanah, \& Ibrahim, H. (2018). Keberhasilan pengobatan tuberkulosis paru di wilayah kerja Puskesmas Panambungan Kota Makassar. Higiene, 4(1), 32-40.

Nurfadillah, Indra, Y., \& Restuastuti, T. (2014). Hubungan pengetahuan dengan tindakan pencegahan penularan pada keluarga penderita tuberkulosis paru di ruang rawat inap 
paru RSUD Arifin Achmad Provinsi Riau. JOM FK, 1(2), 1-9.

Nyasulu, P., Phiri, F., Sikwese, S., Chirwa, T., Singini, I., Banda, H. T., ... Munthali, A. C. (2015). Factors influencing delayed health care seeking among pulmonary tuberculosis suspects in rural communities in Ntcheu District, Malawi, Qualitative Health Research, 1-14. doi: $10.1177 / 1049732315588083$

Oladayo, B., Saheed, G., Ajibola, A., Ndadilnasiya, W., Patrick, N., Peter, N., ... Kabir, S. (2014). Knowledge, care-seeking behavior, and factors associated with patient delay among newly-diagnosed pulmonary tuberculosis patients, Federal Capital Territory, Nigeria, 2010. Pan African Medical Journal, 18(6), 1-5. doi: 10.11694/pamj.supp.2014.18.1.4166

Paul, S., Akter, R., Aftab, A., Khan, A. M., Barua, M., Islam, S., ... Sarker, M. (2015). Knowledge and attitude of key community members towards tuberculosis: mixed method study from BRAC TB control areas in Bangladesh. BMC Public Health, 15(52), 1-8. doi: 10.1186/s12889015-1390-5

Samal, J., \& Dehuri, R. K. (2017). Impact of a structured tuberculosis awareness strategy on the knowledge and behaviour of the families in a slum area in Chhattisgarh, India. Journal of Clinical and Diagnostic Research, 11(3), 11-15.

Sreeramareddy, C. T., Kumar, H. N., \& Arokiasamy, J. T. (2013). Prevalence of self-reported tuberculosis, knowledge about tuberculosis transmission and its determinants among adults in India: Results from a nation-wide cross-sectional household survey. BMC Infectious Diseases, 13(16), 1-9.

Tolossa, D., Medhin, G., \& Legesse, M. (2014). Community knowledge, attitude, and practices towards tuberculosis in Shinile town, Somali regional state, eastern Ethiopia: A cross-sectional study. BMC Public Health, 14(1), 1-13. doi: $10.1186 / 1471-2458-14-804$

World Health Organization. (2018). Global tuberculosis report 2018. World Health Organization. Diperoleh dari https://apps.who.int/iris/handle/1066 5/274453. 